Мелиорация и гидротехника. 2021. Т. 11, № 4. С. 316-331.

Land Reclamation and Hydraulic Engineering. 2021. Vol. 11, no. 4. P. 316-331.

\title{
ГИДРОТЕХНИЧЕСКОЕ СТРОИТЕЛЬСТВО
}

Научная статья

УДК 627.41

doi: 10.31774/2712-9357-2021-11-4-316-331

\section{Обоснование грунтоармированных и грунтонаполняемых конструкций берегозащитных сооружений для условий малых рек}

\section{Денис Владимирович Кашарин}

Южно-Российский государственный политехнический университет (НПИ)

имени М. И. Платова, Новочеркасск, Российская Федерация, dendvk1@mail.ru

Аннотация. Цель: анализ работы берегозащитных сооружений с обоснованием применения грунтоармированных и грунтонаполняемых конструкций для условий малых рек и водотоков гидрографической сети. Материалы и методы. Предложены новые технические решения и технологии возведения оболочечных грунтонаполняемых и грунтоармированных конструкций, обеспечивающих минимальное воздействие на территорию водосбора малых рек. Предлагается применение в качестве основания берегозащитных сооружений грунтонаполняемых оболочек, заполняемых донными отложениями. Результаты. Приводятся аналитические и численные методы определения напряженно-деформированного состояния с учетом свойств материала геосинтетической оболочки грунтонаполняемой конструкции в программном модуле Ansys Mechanical APDL, на основании которых разрабатывается имитационная модель нового технического и технологического решения берегозащитного сооружения, позволяющего обеспечить снижение объемов работ при подготовке и разработке основания. Рассматривается применение лабораторного оборудования для проведения физического моделирования грунтоармированных конструкций берегозащитных сооружений на грунтонаполняемом основании, включая установку для испытания композитных материалов грунтонаполняемой оболочки и напряженно-деформированного состояния грунтоармированного массива. Выводы. Планируемые исследования позволят разработать технологию возведения берегозащитных сооружений, в т. ч. в стесненных городских условиях и на территории природоохранных объектов. По результатам численного моделирования грунтонаполняемых оболочек с применением геотуб предварительно определены условия их устойчивости в качестве основания берегозащитного грунтоармированного сооружения. Предложено при уклонах коренного грунта более $10^{\circ}$ использовать шпунтовую стенку для обеспечения устойчивости оболочки основания. Разработаны лабораторные стенды, обеспечивающие испытание грунтонаполняемой оболочкиоснования и лицевой стенки берегозащитного сооружения.

Ключевые слова: грунтонаполняемая конструкция, берегозащитное сооружение, имитационная модель, грунтонаполняемая оболочка, малый водоток

\section{HYDRAULIC ENGINEERING}

Original article

\section{Substantiation of soil-reinforced and soil-filled structures of bank protection structures for the conditions of small rivers}

\section{Denis V. Kasharin}

South-Russian State Polytechnic University (NPI) named after M. I. Platov, Novocherkassk, Russian Federation, dendvk1@ mail.ru 
Мелиорация и гидротехника. 2021. Т. 11, № 4. С. 316-331.

Land Reclamation and Hydraulic Engineering. 2021. Vol. 11, no. 4. P. 316-331.

Abstract. Purpose: analysis of the bank protection structures operation with substantiation of soil-reinforced and soil-filled structures use for the conditions of small rivers and watercourses of hydrographic network. Materials and methods. New technical solutions and technologies for the construction of shell soil-filled and soil-reinforced structures, which provide a minimum impact on the catchment area of small rivers are proposed. The soil-filled shells filled with bottom sediments are proposed as the base of bank protection structures. Results. Analytical and numerical methods for determining the stress-strain state are given, taking into account the properties of geosynthetic shell material of a soil-filled structure in the software module Ansys Mechanical APDL, on the basis of which a simulation model of a new technical and technological solution of a bank protection structure is developed, which allows to reduce scope of work in preparing and developing the foundation. The use of laboratory equipment for physical modeling of bank protection soil-reinforced structures on a soilfilled foundation, including an installation for testing composite materials of a soil-filled shell and the stress-strain state of a soil-reinforced massif is considered. Conclusions. The planned research will make it possible to develop a technology of bank protection structures construction, both in cluttered urban environment and on the territory of environmental facilities. Based on the results of numerical modeling of soil-filled shells with the application of geotubes, the conditions for their stability as the foundation of a bank protection soil-reinforced structure were preliminarily determined. It is proposed to use a sheet pile wall at slopes of bedrock more than $10^{\circ}$ to ensure the stability of the base shell. Laboratory stands to test the soil-filled shellbases and the front wall of the bank protection structure have been developed.

Keywords: soil-filled structure, bank protection structure, simulation model, soil-filled shells, small watercourse

Введение. При строительстве берегозащитных сооружений, обладающих значительной протяженностью, основными проблемами являются значительная неоднородность основания аллювиального происхождения, существенные воздействия руслоформирующих процессов и необходимость соблюдения экологических требований при проведении строительных работ, ремонта и реконструкции.

В случае существующих жестких конструкций берегозащитных сооружений даже незначительная деформация основания может привести к разрушению конструкции в целом (рисунок $1 a$ ). В связи с этим одной из наиболее сложных задач является подготовка и стабилизация оснований, также необходимы значительные капиталозатраты при их строительстве и реконструкции. Преимуществом гибких габионных конструкций является способность воспринимать без разрушения значительные просадки основания, но доступный для их заполнения материал не всегда соответствует природно-климатическим условиям и разрушается при циклах за- 
мораживания и оттаивания, что приводит к его высыпанию через ячейки сетки габионов и, как следствие, к нарушению устойчивости берегозащитного сооружения в целом (рисунок 1б). Биопозитивные фашинные конструкции не обеспечивают достаточную надежность крепления и имеют малый срок службы в условиях переменного уровня воды и колебаний температур [1-7].

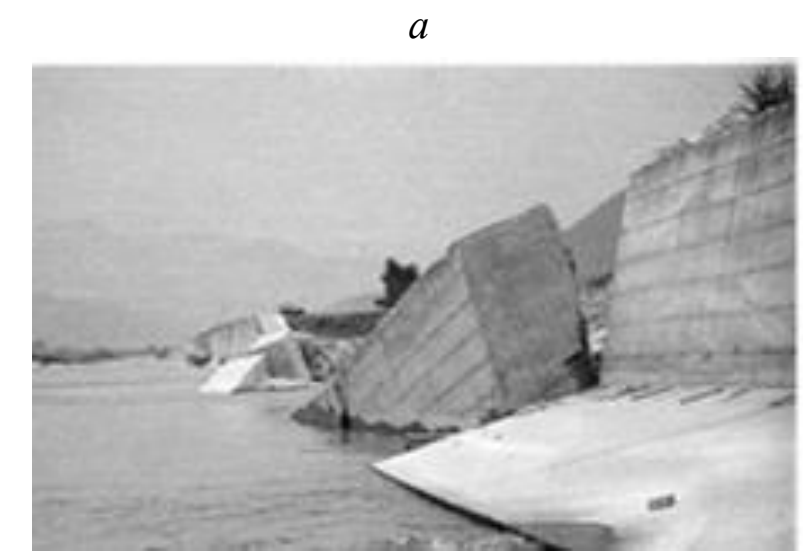

6

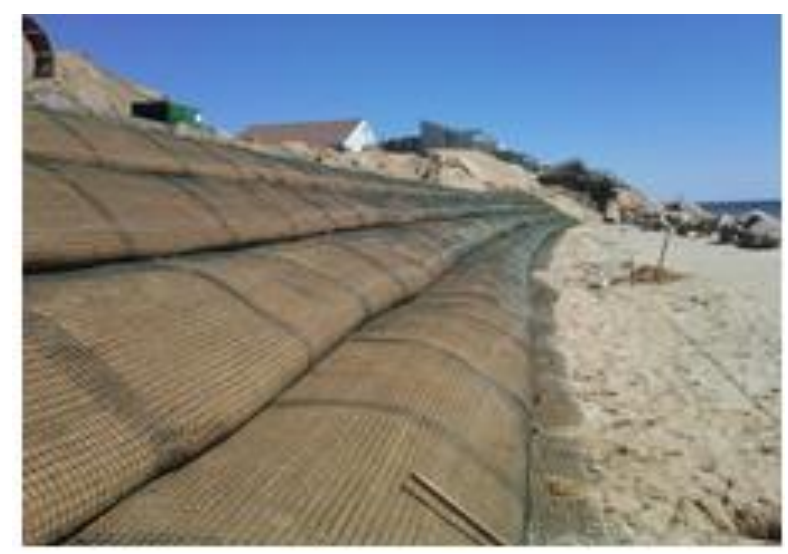

$a$ - грунтоармированная конструкция; $\sigma$ - грунтонаполняемые конструкции

\section{Рисунок 1 - Разрушение различных конструкций берегозащитных сооружений $[5,8]$}

Целью исследования являлся анализ существующих берегозащитных сооружений и обоснование применения берегозащитных сооружений с использованием грунтоармированных и грунтонаполняемых конструкций, а также технологии их возведения.

При отсутствии качественного местного строительного материала 
наиболее эффективным является использование грунтоармированных и грунтонаполняемых конструкций Longard, TenCate, Soiltrain, OOО «Русгеосинт» и др., применение которых известно с середины прошлого века и позволяет обеспечить устойчивость грунтовых массивов в условиях просадочных грунтов и при опасных геологических процессах (рисунок 1) [7-10].

Материалы и методы. Основным недостатком существующих защитных сооружений является значительный вес лицевой стенки, что увеличивает неравномерность нагрузки на армированный массив и его основание.

Вторым аспектом является значительное воздействие на водный объект и территорию его водосбора при проведении подготовительных работ: расчистка донных отложений и подготовка основания сооружений, складирование отложений с необходимостью осветления, а иногда вывоза на специализированные площадки хранения $[11,12]$.

При этом глубину заложения основания берегозащитного сооружения следует назначать ниже возможного размыва грунта с учетом воздействия проектируемой конструкции и толщины активного слоя наносов. Прочностные, деформационные и фильтрационные характеристики биогенных грунтов и илов определяются в диапазоне давлений, соответствующих напряженному состоянию после возведения сооружения. Если под его основанием залегает слой грунта с модулем упругости $E<5$ МПа и толщиной более его ширины, то осадка должна определяться с учетом полного давления $p$ (кПа) под ним, не превышающего расчетного сопротивления грунта основания $R$ (кПа), определяемого по известным нормативным формулам [13].

В случае медленно уплотняющихся водонасыщенных связных и биогенных грунтов основания, имеющих степень влажности $S_{r} \geq 0,85$ и коэффициент консолидации $c v \leq 10^{7} \mathrm{~cm}^{2} /$ год, сила предельного сопротивления рассчитывается с учетом избыточного давления воды в порах $u$ (кПа), вызывающего нестабилизированное состояние. 
Наличие нестабилизированного состояния основания с изменяющейся по времени при консолидации анизотропией прочностных, деформационных и фильтрационных характеристик, а также значительной тиксотропии илов приводит к увеличению сроков строительства, которое должно производиться с учетом времени, необходимого для достижения заданной степени консолидации основания, а также конечной осадки основания под пригрузкой $[7,8]$.

При расчетных деформациях грунта основания, сложенного биогенными грунтами и илами, больше предельных, предусматриваются следующие мероприятия $[7,11,12]$ : вытеснение грунта основанием при толщине биогенных грунтов и илов не более 0,2 м; полная или частичная прорезка слоев биогенных грунтов и илов при устройстве основания; полная или частичная замена биогенного грунта или ила песком, гравием, щебнем и т. д.; уплотнение грунтов временной или постоянной пригрузкой основания сооружения или всей площадки строительства насыпным (намывным) грунтом; применение грунтоармированных или грунтонаполняемых конструкций с горизонтальной схемой армирования при толщине биогенных грунтов и илов более 1,5 м [8].

Для условий возведения на слабых биогенных грунтах С. И. Сахаровой предусматривалось возведение армированных грунтовых подушек, которые существенно повышают устойчивость [12].

Недостатком является то, что при устройстве основания предполагается использование технологии, при которой необходимо осуществить установку грунтоармированных элементов в специально подготовленную траншею и предварительное уплотнение грунта, это значительно усложняет производство работ в условиях береговой зоны.

В настоящее время складирование донных отложений после проведения подготовительных работ возможно с применением геотуб из фильтрующего геотекстиля, которые в настоящее время широко используются 
как зарубежными, так и отечественными производителями. Применение таких конструкций обеспечивает уменьшение объема за счет обезвоживания донных отложений. Однако, несмотря на уменьшение площади складирования донных отложений, необходимы дополнительные мероприятия по отводу осветленного стока и замещению изъятого материала в основании берегозащитного сооружения.

В связи с этим наиболее перспективным является использование комбинирования технологии создания грунтонаполняемых конструкций основания берегозащитных сооружений за счет применения геотуб без изъятия материала из прибрежной зоны водного объекта.

При расчетном обосновании берегозащитного сооружения необходимо учитывать дополнительное воздействие водного потока, так как он оказывает взвешивающее фильтрационное, волновое, абразивное и иные виды воздействий, в т. ч. ледовые. Расчетные положения для определения устойчивости берегозащитных сооружений к воздействию данных явлений хорошо изучены [7]. При строительстве берегозащитных сооружений с применением армированного грунта снижение веса лицевой стенки обеспечивает надежную защиту от приведенных выше видов воздействий. Это дает снижение нагрузки на основание берегозащитного сооружения и армированный массив, упрощает технологический процесс возведения данных сооружений. Предлагается использование гибких лицевых стенок из геотекстиля и сборных лицевых стенок из композитных материалов.

Результаты и обсуждение. Рассмотрим предлагаемые технические и технологические решения по возведению берегозащитных сооружений. Нами разработаны новые технические решения грунтоармированных сооружений, позволяющих обеспечить наименьший вес конструкции за счет применения гибкой лицевой стенки из геосинтетического материала и грунтонаполняемого основания (рисунок 2).

Преимуществом конструкций на рисунке 2 является возможность их 
возведения без применения тяжелой строительной техники в условиях отсутствия развитой транспортной инфраструктуры или в стесненных условиях городской среды. Рассматривается возможность применения в качестве основания грунтонаполняемой оболочки, выполненной из водопроницаемого геотекстиля (геотубы), в которую закачивается пульпа под давлением, превосходящим в несколько раз давление окружающего грунта, это обеспечивает снижение его влажности с 80 до 40 \% и более. Грунтонаполняемая оболочка укладывается на освобожденный под действием гидромонитора коренной устойчивый грунт. Плотность грунта внутри оболочки может быть увеличена до 1,8 т/м³. При необходимости для стабилизации грунта в геотубе добавляется отвердитель.

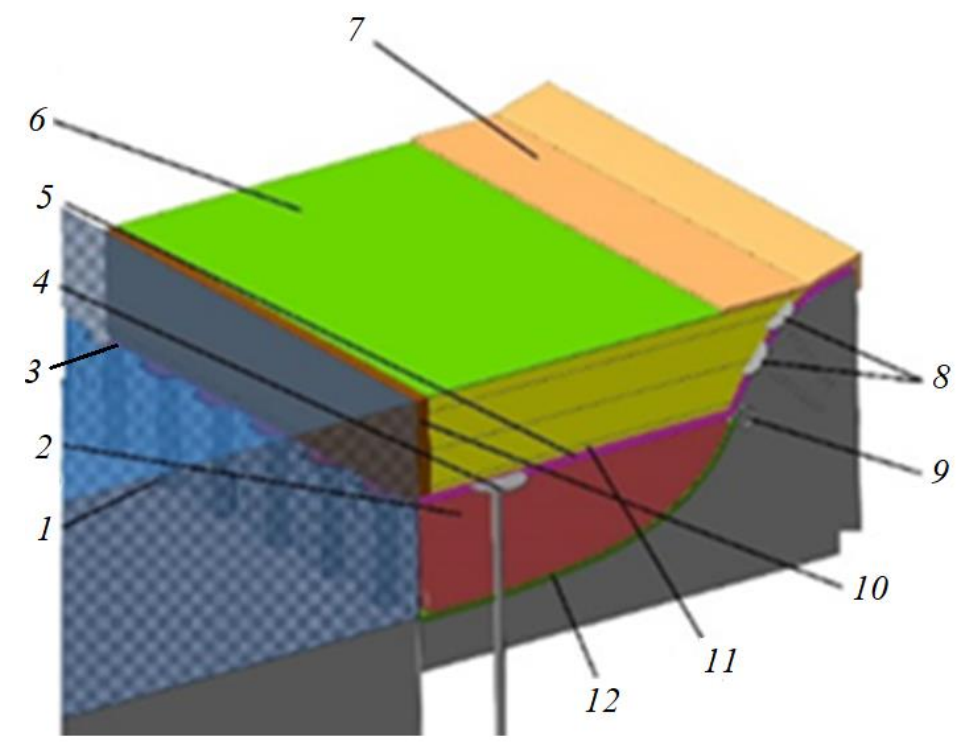

1 - крепление шпунтовых стенок; 2 - геотуба; 3 - лицевая стенка; 4 - анкер; 5 - геотекстиль; 6 - грунтоармированный массив, армированный полимерными лентами; 7 - противофильтрационная оболочка; 8 - грунтонаполняемые армирующие оболочки; 9 - дренажная система; 10 - шпунт; 11 - грунтоармированный массив; 12 - основание геотуб из полимерного материала

\section{Рисунок 2 - Конструкция берегозащитного сооружения с применением грунтоармированных и грунтонаполняемых оболочек (патент РФ 2714732) [13]}

Грунтонаполняемая оболочка обеспечивает надежное основание берегозащитному сооружению, однако при уклоне границы коренного грунта более $10^{\circ}$ не обеспечивается ее устойчивость. Предлагается обеспечить ее 
устойчивое положение за счет шпунтовой стенки, ограничивающей ее перемещение вниз по склону.

Параметрами грунтонаполняемых конструкций являются: протяженность и их ширина, внешние и внутренние нагрузки, допустимый уклон основания.

Техническими критериями обоснования конструкций являются: давление в грунтонаполняемой конструкции, обеспечение устойчивости к опрокидыванию, градиент фильтрации, осадка конструкции.

Рассмотрим вопросы численного моделирования предлагаемых технических решений. Последовательность численного моделирования грунтонаполняемых конструкций состоит из приведенных ниже этапов.

Строятся начальные сечения грунтонаполняемых конструкций с использованием эластиков Эйлера (рисунок 3).

1 Расчет грунтонаполняемой конструкции, состоящей из грунтонаполняемых оболочек, основывается на рассмотрении веревочной кривой, нагруженной давлением грунта, при использовании следующих зависимостей $[8,9]$ :

$$
\begin{gathered}
\left\{\begin{array}{l}
y_{1 a}=h_{1}\left[1-\sqrt{1-k_{1}^{2} \sin ^{2} \alpha_{1}}\right] \\
x_{1 a}=h_{1}\left[E_{2}\left(\alpha_{1}, k_{1}\right)-\left(1-\frac{k_{1}^{2}}{2}\right) E_{1}\left(\alpha_{1}, k_{1}\right)\right]
\end{array}\right. \\
\left\{\begin{array}{l}
y_{2 a}=h_{2}\left[\sqrt{\left(1-k_{2}^{2} \sin ^{2} \alpha_{2}\right) /\left(1-k_{2}^{2}\right)}-1\right] \\
x_{2 a}=h_{2} \frac{1-k_{2}^{2}}{2\left[E_{1}\left(\pi / 2, k_{2}\right)-E_{1}\left(\alpha_{2}, k_{2}\right)\right]-\left[E_{2}\left(\pi / 2, k_{2}\right)-E_{2}\left(\alpha_{2}, k_{2}\right)\right]} / \sqrt{1-k_{2}^{2}},
\end{array}\right.
\end{gathered}
$$

где $y_{1 a}$ и $y_{2 a}$ - соответственно ординаты расчетной схемы оболочки, м;

$x_{1 a}$ и $x_{2 a}$ - соответственно абсциссы расчетной схемы оболочки, м;

$h_{1}$ и $h_{2}$ - соответственно параметры эластик, м;

$k_{1}$ и $k_{2}$ - соответственно модули эллиптического интеграла, м; 
Мелиорация и гидротехника. 2021. Т. 11, № 4. С. 316-331.

Land Reclamation and Hydraulic Engineering. 2021. Vol. 11, no. 4. P. 316-331.

$E_{1}$ и $E_{2}$ - эллиптические интегралы 2-го рода соответственно верхней и нижней части оболочки.
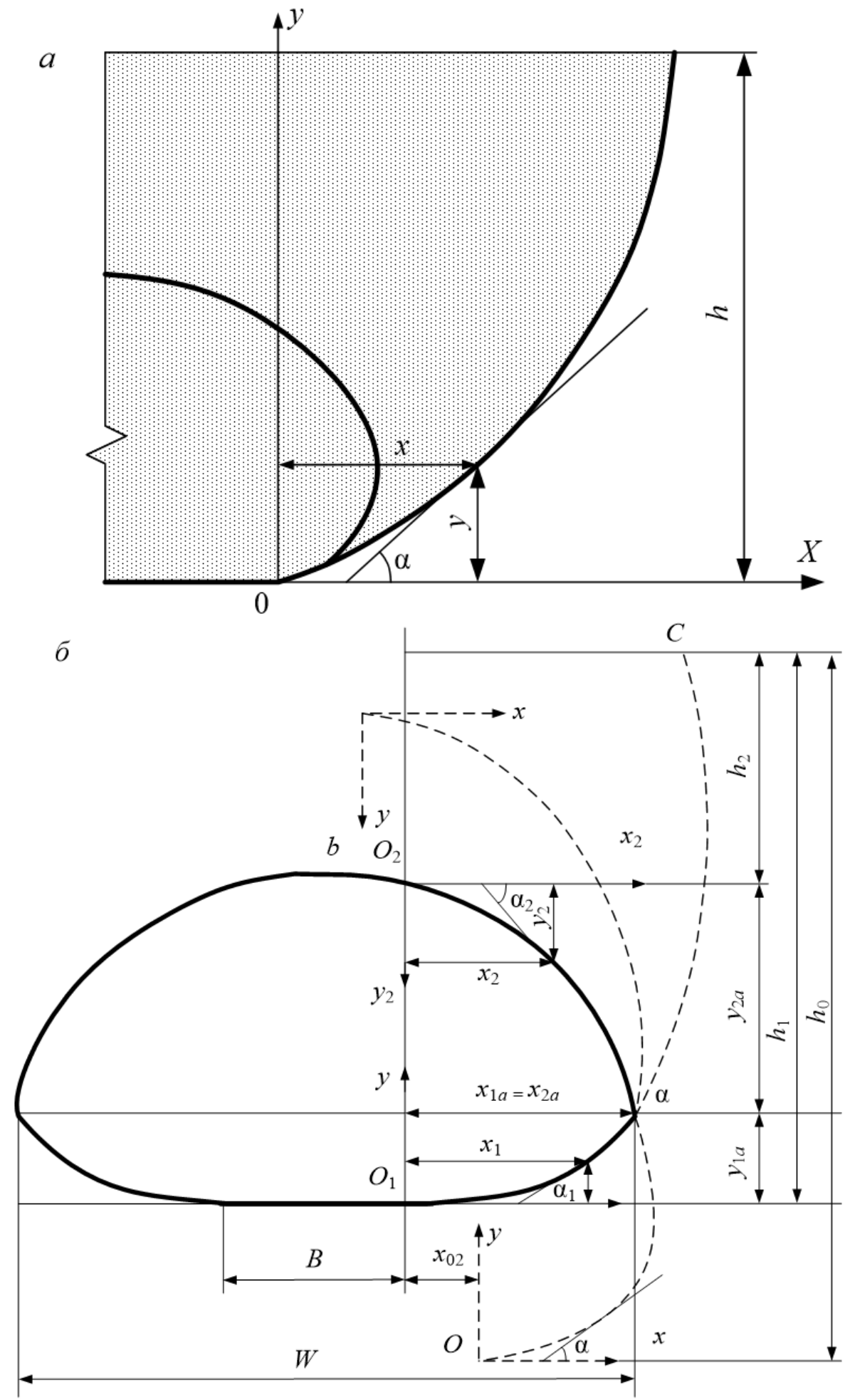

$W, B$ - соответственно ширина оболочки по низу и ее прилегание к основанию, м; $b$ - ширина оболочки, м; $\alpha, \alpha_{1}$ - углы касательной к оболочке; $h, h_{0}, h_{1}, h_{2}$ - высоты положения расчетных точек оболочки, м

\section{Рисунок 3 - Расчетная схема оболочки}


2 Определяется напряженно-деформированное состояние с учетом свойств материала геосинтетической оболочки грунтонаполняемой конструкции и предварительного ее очертания по зависимостям (1), (2) в модуле Ansys Mechanical APDL, для моделирования оболочки и основания использованы конечные элементы SHELL 181 и SOLID 185, контактную пару между оболочкой и основанием моделировали с помощью CONTA174 («контактная поверхность») и TARGE170 («целевая поверхность»). При этом множитель штрафной жесткости в направлении нормали $\mathrm{FKN}=0,1$. Коэффициент трения между оболочкой и основанием равен 0,3 , множитель допуска внедрения FTOLN $=0,1$, когезия в контакте $\mathrm{COHE}=0$, максимально допускаемое контактное давление TNOP = 7 МПа.

3 Моделирование контакта между заполнителем, оболочкой, шпунтовой стенкой и ее основанием [13].

4 Создание модели грунта с использованием усовершенствованной модели Друкера - Прагера (EDP) [14-16].

Предварительные результаты численного моделирования в модуле Ansys Mechanical APDL при уклоне коренного русла $10^{\circ}$, коэффициенте трения геосинтетической оболочки о грунт, равном 0,3 , плотности грунта в оболочке 1,8 т/м $\mathrm{M}^{3}$ и периметре оболочки 2 м представлены на рисунке 4 .
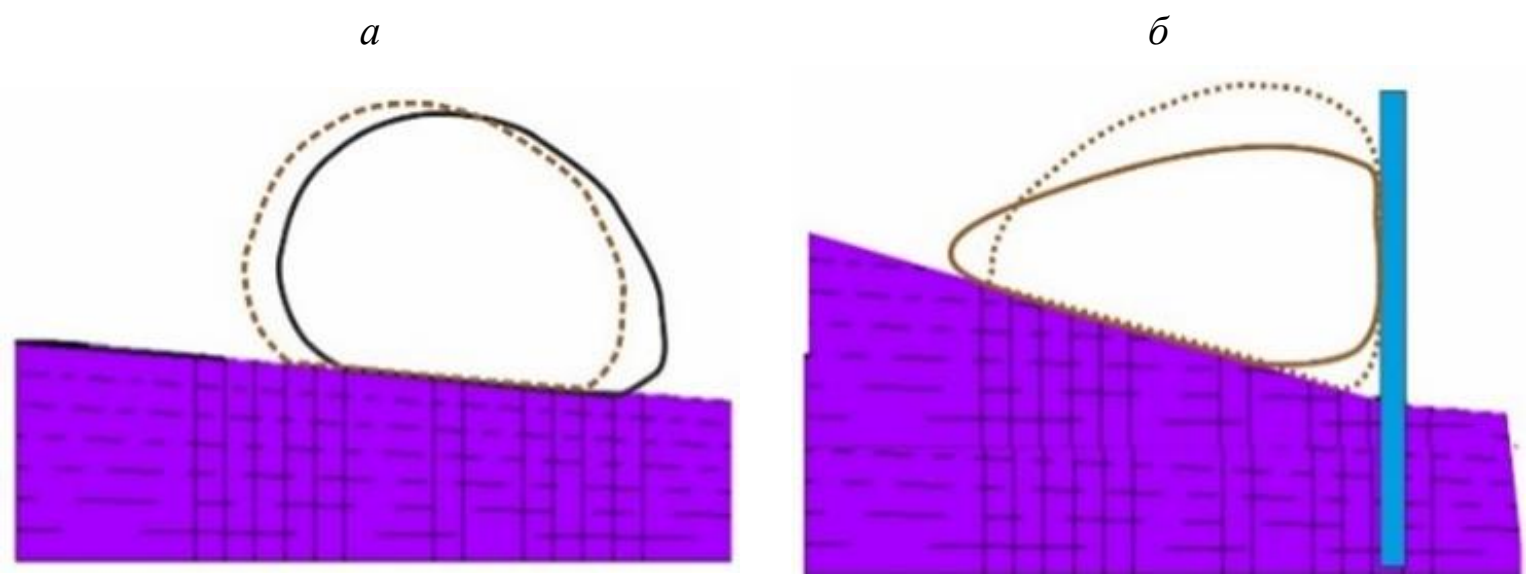

$a$ - без шпунтовой стенки; $\sigma$ - с применением шпунтовой стенки

Рисунок 4 - Результаты численного моделирования устойчивости грунтонаполняемой оболочки 
Использование данной последовательности позволит определить предварительные условия обеспечения устойчивого положения оболочки, оценить напряженно-деформированное состояние и определить прочностные свойства геосинтетического материала $[17,18]$.

Так как формообразование грунтонаполняемых оболочек является сложным процессом, с учетом изменения качественных характеристик грунта необходимо проведение дополнительных лабораторных исследований, результаты которых должны внести корректировки в данные численного моделирования [19-22].

С целью испытания прочности материалов оболочки разработаны лабораторные стенды для определения напряженно-деформированного состояния грунтонаполняемой оболочки при различных показателях давления, влажности грунта и коэффициентов фильтрации через тело оболочки с возможностью моделирования коэффициента трения оболочки и поверхности основания, а также изменения ее наклона от 0 до $25^{\circ}$.

Для наблюдения за геометрическими параметрами оболочки предусмотрены видеокамеры, а для наполнения оболочки пульпопровод.

Общий вид лабораторного стенда представлен на рисунке 5.

Для испытания лицевой стенки и армирующих элементов берегозащитного сооружения предусмотрено создание лабораторного стенда с возможностью обеспечения вырывающего усилия как на лицевую стенку, так и на элементы ее армирования за счет применения натяжного устройства, а также общей нагрузки на грунтоармированный массив и вибростенд, обеспечивающей моделирование сейсмических воздействий (рисунок 6).

В дальнейшем предполагается после проведения лабораторных испытаний внести корректировку в параметры технического решения и проверить достоверность результатов численного моделирования. 
Мелиорация и гидротехника. 2021. Т. 11, № 4. С. 316-331.

Land Reclamation and Hydraulic Engineering. 2021. Vol. 11, no. 4. P. 316-331.

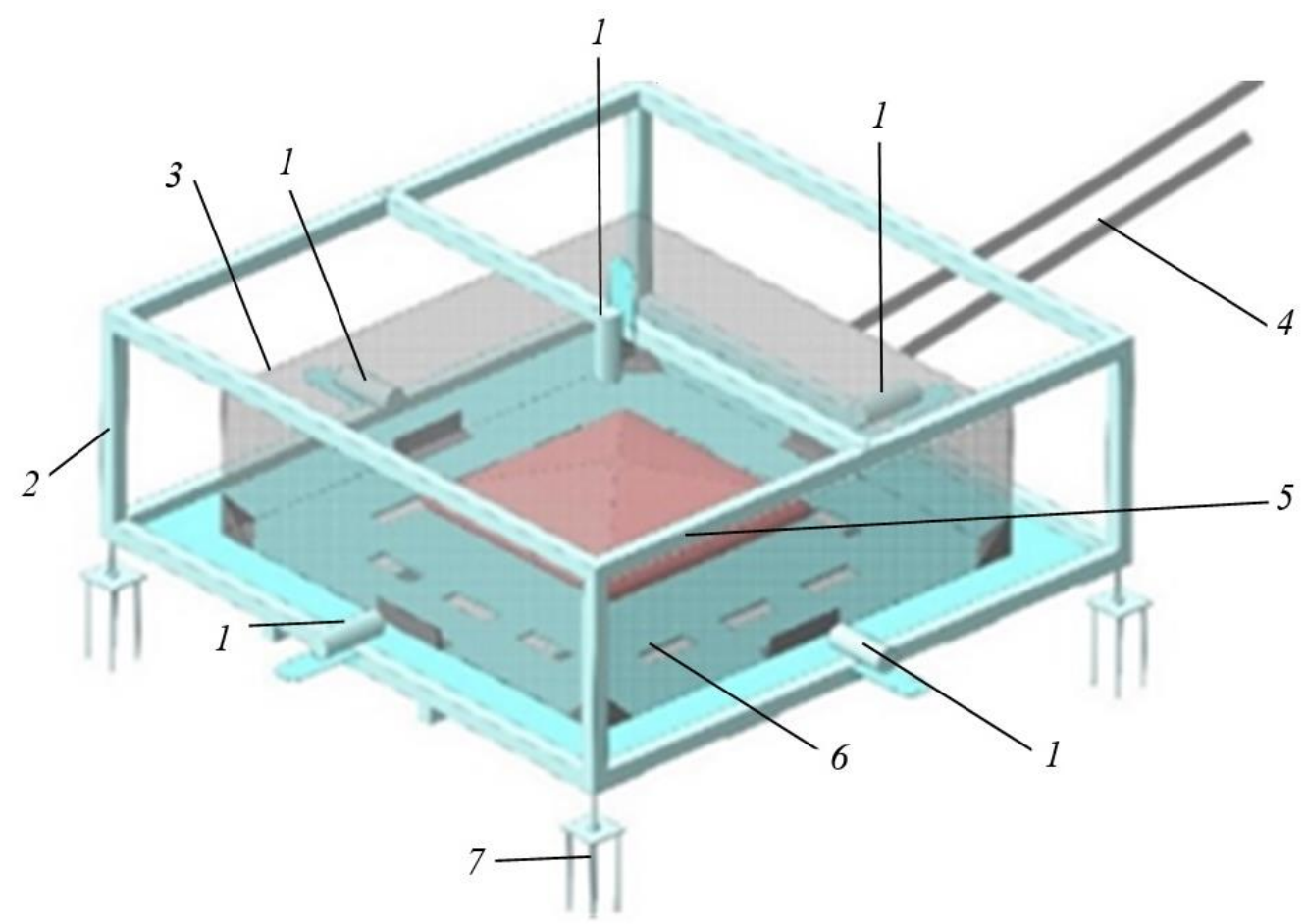

1 - камеры; 2 - рама; 3 - защитный экран из оргстекла; 4 - подводящие воздуховоды от компрессора; 5 - образец оболочки, прикрепленной к стальной раме; 6 - основание с перфорацией; 7 - фиксирующие опоры

\section{Рисунок 5 - Лабораторный стенд для испытания прочности материалов оболочки}

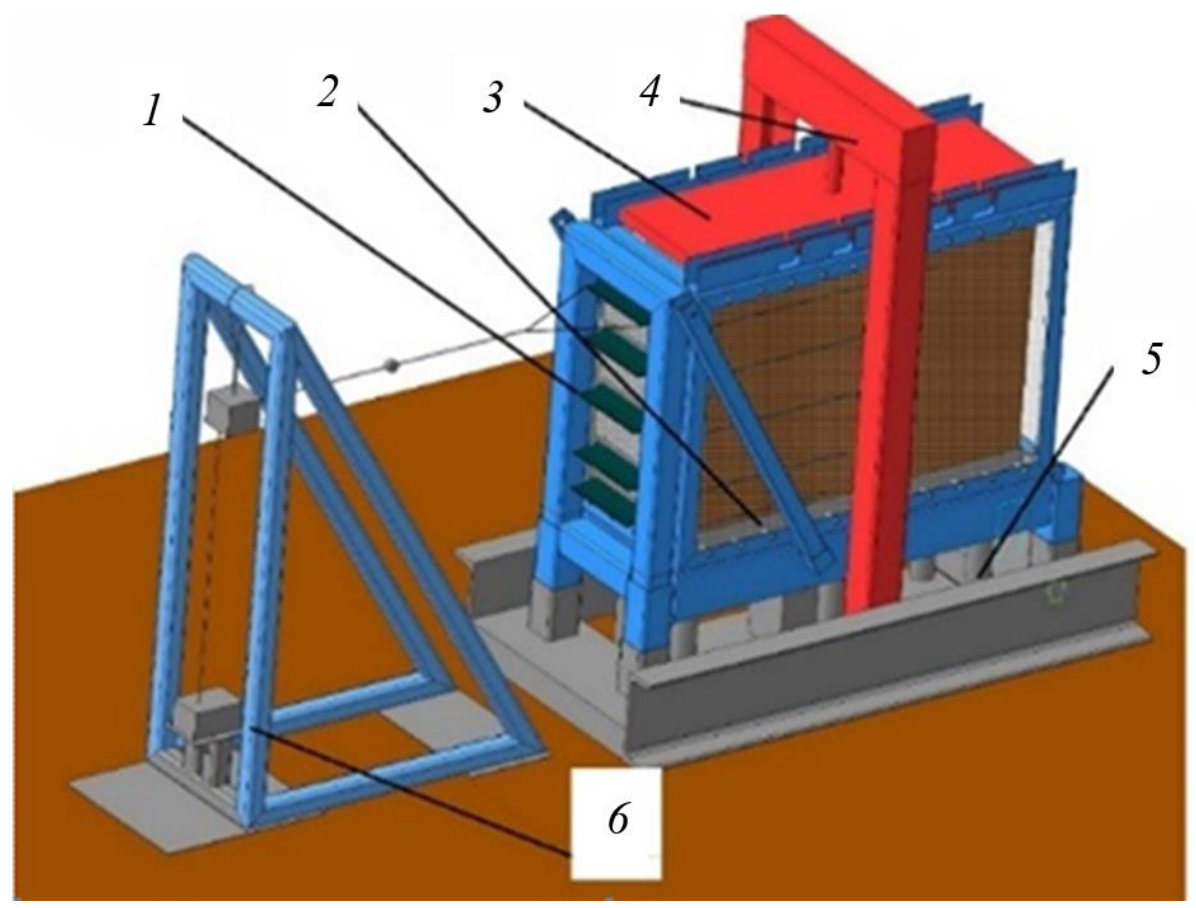

1 - лоток; 2 - рама лотка (для закрепления лицевой стенки); 3 - щит для равномерного распределения нагрузки; 4 - пресс; 5 - вибростол; 6 - натяжное устройство

Рисунок 6 - Схема установки для испытания грунтоармированных и грунтонаполняемых конструкций 
Мелиорация и гидротехника. 2021. Т. 11, № 4. С. 316-331.

Land Reclamation and Hydraulic Engineering. 2021. Vol. 11, no. 4. P. 316-331.

Выводы. В результате анализа существующих конструкций берегозащитных сооружений предлагаются новые технические решения и технологии возведения берегозащитных сооружений с применением грунтоармированных и грунтонаполняемых конструкций, позволяющих обеспечить снижение объемов работ при подготовке и разработке их основания за счет использования донных отложений без изъятия из прибрежной зоны водного объекта.

По результатам численного моделирования грунтонаполняемых оболочек с применением геотуб предварительно определены условия их устойчивости в качестве основания берегозащитного грунтоармированного сооружения. Предложено при уклонах коренного грунта более $10^{\circ}$ использовать шпунтовую стенку для обеспечения устойчивости оболочки основания.

Разработаны лабораторные стенды, обеспечивающие испытание грунтонаполняемой оболочки-основания и лицевой стенки берегозащитного сооружения.

\section{Список источников}

1. Прокопов А. Ю., Лебидко В. А. Выбор и обоснование методов берегоукрепления (на примере р. Кубань в г. Краснодаре) // Известия Ростовского государственного строительного университета. 2015. Т. 2, № 20. С. 41-48.

2. Михасек А. А., Смывалов А. А. Основы выбора конструкции берегоукрепления из композитных материалов // Научное обозрение. 2015. № 14. С. 102-108.

3. Яркин В. В., Кухарь А. В. Сравнительный анализ решений по берегоукреплению побережья Азовского моря вертикальными стенками из заанкеренного шпунта различной конструкции // Металлические конструкции. 2018. Т. 24, № 4. С. 157-166.

4. Забара А. И. Берегоукрепление Сахалина или надежен ли берег острова // Экологический вестник России. 2015. № 3. С. 36-38.

5. Кашарин Д. В. Обоснование возведения оснований грунтоармированных берегозащитных сооружений для условий малых водотоков // Механика грунтов в геотехнике и фундаментостроении: материалы междунар. науч.-техн. конф. Новочеркасск, 2018. С. 663-671.

6. Курбанов С. О., Созаев А. А. Проблемы инженерной защиты и природоохранного обустройства прибрежных урбанизированных зон малых рек на Юге России // Политематический сетевой электронный научный журнал Кубанского государственного аграрного университета [Электронный ресурс]. 2016. № 118(04). C. 916-936. URL: http:ej.kubagro.ru/2016/04/pdf/55.pdf (дата обращения: 01.10.2021).

7. Кашарин Д. В. Методы расчета грунтоармированных флютбетов мобильных 
сооружений на слабых грунтах // Известия Всероссийского научно-исследовательского института гидротехники им. Б. Е. Веденеева. 2011. Т. 264. С. 43-55.

8. Кашарин Д. В. Защитные инженерные сооружения из композитных материалов в водохозяйственном строительстве: монография. Новочеркасск: ЮРГТУ (НПИ), 2012. $343 \mathrm{c}$.

9. Uso de geossintéticos como reforço em estradas não pavimentadas / L. Oliveira, P. Viana, D. Santos, E. Reis // Journal of the Brazilian Association of Agricultural Engineering. 2016. Vol. 36, № 3. P. 546-557. http:dx.doi.org/10.1590/1809-4430-Eng.Agric.v36n3p546$557 / 2016$.

10. Guo W., Chu J., Yan S. Analytical and numerical studies of geosynthetic tubes resting on deformable foundations // Geotechnical Special Publication. 2014. 2(238). P. 503-514. DOI: $10.1061 / 9780784413401.050$.

11. Янин Е. П. Техногенные речные илы в зоне влияния промышленного города (формирование, состав, геохимические особенности). М.: ИМГРЭ, 2002. 100 с.

12. Сахарова С. И. Армированные грунтовые подушки как основания гидротехнических сооружений мелиоративных систем в торфах. М.: Моск. гидромелиоратив. ин-т, 1990. 290 с.

13. Берегозащитное сооружение с применением грунтоармированных и грунтонаполняемых оболочек: пат. 2714732 Рос. Федерация: МПК Е 02 В 3/06, Е 02 В 3/12 / Кашарин Д. В., Калмыков С. А., Плотникова В. А.; заявитель и патентообладатель Юж.-Рос. гос. политехн. ун-т (НПИ) им. М. И. Платова. № 2018146758; заявл. 27.12.18; опубл. 19.02.20, Бюл. № 5.9 с.

14. Хуберян К. М. Основы расчета мягких оболочек и пластин при помощи смешанного вариационно-стержневого метода. Статика и динамика гибких систем. М.: Стройиздат, 1987. 246 с.

15. Loginova I., Artamonova D., Stolyarov O. Relationship between structure and viscoelastic properties of geosynthetics // MATEC Web of Conferences. 2016. 53(01). 01015. DOI: $10.1051 /$ matecconf/20165301015.

16. Vasiluta P., Cofaru N., Cofaru I. I. Studies on predictive virtual models based on finite element analysis of the behaviour of geomembranes // MATEC Web of Conferences. 2017. 137(18). 06006. DOI: 10.1051/matecconf/201713706006.

17. Bhandari A., Han J. Two-dimensional physical modelling of soil displacements above trapdoors // Geotechnical Research. 2018. № 5(2). P. 68-80. https:doi.org/10.1680/ jgere.18.00002.

18. Hasan M., Samadhiya N. K. Experimental and numerical analysis of geosyntheticreinforced floating granular piles in soft clays // International Journal of Geosynthetics and Ground Engineering. 2016. № 2(3). Article number: 22. https:doi.org/10.1007/s40891-0160062-6.

19. Bacas B. M., Cañizal J., Konietzky H. Frictional behaviour of three critical geosynthetic interfaces // Geosynthetics International. 2015. Vol. 22, № 5. P. 355-365. https:doi.org/ 10.1680/jgein.15.00017.

20. Tajabadipour M., Marandi M. Effect of rubber tire chips-sand mixtures on performance of geosynthetic reinforced earth walls // Periodica Polytechnica Civil Engineering. 2017. Vol. 61. P. 322-334. https:doi.org/10.3311/PPci.9539.

21. Abd A., Utili S. Design of geosynthetic-reinforced slopes in cohesive backfills // Geotextiles and Geomembranes. 2017. № 45(6). P. 627-641. https:doi.org/10.1016/j.geotex mem.2017.08.004.

22. Kim M., Filz G. M., Plaut R. H. Two-chambered water-filled geomembrane tubes used as water barriers: experiments and analysis // Geosynthetics International. 2005. Vol. 12, № 3. P. 127-133. https:doi.org/10.1680/gein.2005.12.3.127. 
Мелиорация и гидротехника. 2021. Т. 11, № 4. С. 316-331.

Land Reclamation and Hydraulic Engineering. 2021. Vol. 11, no. 4. P. 316-331.

\section{References}

1. Prokopov A.Yu., Lebidko V.A., 2015. Vybor i obosnovanie metodov beregoukrepleniya (na primere $r$. Kuban' $v$ g. Krasnodare) [Selection and substantiation of bank protection methods (on the example of the Kuban River in Krasnodar)]. Izvestiya Rostovskogo gosudarstvennogo stroitel'nogo universiteta [Bulletin of Rostov State University of Civil Engineering], vol. 2, no. 20, pp. 41-48. (In Russian).

2. Mikhasek A.A., Smyvalov A.A., 2015. Osnovy vybora konstruktsii beregoukrepleniya iz kompozitnykh materialov [Fundamentals of choosing the composite material design for bank reinforcement]. Nauchnoe obozrenie [Scientific Review], no. 14, pp. 102-108. (In Russian).

3. Yarkin V.V., Kukhar A.V., 2018. Sravnitel'nyy analiz resheniy po beregoukrepleniyu poberezh'ya Azovskogo morya vertikal'nymi stenkami iz zaankerennogo shpunta razlichnoy konstruktsii [Comparative analysis of solutions for protection of the coast of the Azov Sea by anchored vertical walls of sheet pile of various design]. Metallicheskie konstruktsii [Metal Constructions], vol. 24, no. 4, pp. 157-166. (In Russian).

4. Zabara A.I., 2015. Beregoukreplenie Sakhalina ili nadezhen li bereg ostrova [Coast protection of Sakhalin or whether the coast of the island is reliable]. Ekologicheskiy vestnik Rossii [Ecological Bulletin of Russia], no. 3, pp. 36-38. (In Russian).

5. Kasharin D.V., 2018. Obosnovanie vozvedeniya osnovaniy gruntoarmirovannykh beregozashchitnykh sooruzheniy dlya usloviy malykh vodotokov [Substantiation of the construction of foundations of soil-reinforced coastal protection structures for the conditions of small watercourses]. Mekhanika gruntov $v$ geotekhnike $i$ fundamentostroenii: materialy mezhdunarodnoy nauchno-tekhnicheskoy konferentsii [Soil Mechanics in Geotechnics and Foundation Engineering: Proc. of the International Scientific and Technical Conference]. Novocherkassk, pp. 663-671. (In Russian).

6. Kurbanov S.O., Sozaev A.A., 2016. [Problems of engineering protection and environmental protection of costal urban zones of small rivers in the South of Russia]. Nauchnyy zhurnal KubGAU: politematicheskiy setevoy elektronnyy zhurnal, no. 118(04), pp. 916-936, available: http: ej.kubagro.ru/2016/04/pdf/55.pdf [accessed 01.10.2021]. (In Russian).

7. Kasharin D.V., 2011. Metody rascheta gruntoarmirovannykh flyutbetov mobil'nykh sooruzheniy na slabykh gruntakh [Method for calculating soil-reinforced flood beds for mobile structures on soft soils]. Izvestiya Vserossiyskogo nauchno-issledovatel'skogo instituta gidrotekhniki im. B. E. Vedeneeva [Bulletin of the All-Russian Scientific Research Institute of Hydraulic Engineering by B.E. Vedeneev], vol. 264, pp. 43-55. (In Russian).

8. Kasharin D.V., 2012. Zashchitnye inzhenernye sooruzheniya iz kompozitnykh materialov v vodokhozyaystvennom stroitel'stve: monografiya [Protective Engineering Structures from Composite Materials in Water Management: monograph]. Novocherkassk, YRSTU (NPI), 343 p. (In Russian).

9. Oliveira L., Viana P., Santos D., Reis E., 2016. Uso de geossintéticos como reforço em estradas não pavimentadas. Journal of the Brazilian Association of Agricultural Engineering, vol. 36, no. 3, pp. 546-557, http:dx.doi.org/10.1590/1809-4430-Eng.Agric.v36n3p546557/2016. (In Portuguese).

10. Guo W., Chu J., Yan S., 2014. Analytical and numerical studies of geosynthetic tubes resting on deformable foundations. Geotechnical Special Publication, 2(238), pp. 503-514, DOI: $10.1061 / 9780784413401.050$.

11. Yanin E.P., 2002. Tekhnogennye rechnye ily $v$ zone vliyaniya promyshlennogo goroda (formirovanie, sostav, geokhimicheskie osobennosti) [Technogenic River Silts in the Zone of Industrial City Influence (Formation, Composition, Geochemical Features)]. Moscow, IMGRE Publ., 100 p. (In Russian).

12. Sakharova S.I., 1990. Armirovannye gruntovye podushki kak osnovaniya gidro- 
tekhnicheskikh sooruzheniy meliorativnykh sistem v torfakh [Reinforced Ground Pads as Bases of Hydraulic Engineering Structures for Reclamation Systems in Peat]. Moscow, Moscow Irrigation and Drainage Institute, 290 p. (In Russian).

13. Kasharin D.V., Kalmykov S.A., Plotnikova V.A., 2018. Beregozashchitnoe sooruzhenie s primeneniem gruntoarmirovannykh i gruntonapolnyaemykh obolochek [Bank Protection Structure Using Soil-Reinforced and Soil-Filled Shells]. Patent RF, no. 2714732. (In Russian).

14. Khuberyan K.M., 1987. Osnovy rascheta myagkikh obolochek $i$ plastin pri pomoshchi smeshannogo variatsionno-sterzhnevogo metoda. Statika i dinamika gibkikh sistem [Fundamentals of Computation of Soft Shells and Plates Using a Mixed Variational-rod Method. Statics and Dynamics of Flexible Systems]. Moscow, Stroyizdat Publ., 246 p. (In Russian).

15. Loginova I., Artamonova D., Stolyarov O., 2016. Relationship between structure and viscoelastic properties of geosynthetics. MATEC Web of Conferences, 53(01), 01015, DOI: $10.1051 /$ matecconf/20165301015.

16. Vasiluta P., Cofaru N., Cofaru I.I., 2017. Studies on predictive virtual models based on finite element analysis of the behaviour of geomembranes. MATEC Web of Conferences, 137(18), 06006, DOI: 10.1051/matecconf/201713706006.

17. Bhandari A., Han J., 2018. Two-dimensional physical modelling of soil displacements above trapdoors. Geotechnical Research, no. 5(2), pp. 68-80, https:doi.org/10.1680/ jgere.18.00002.

18. Hasan M., Samadhiya N.K., 2016. Experimental and numerical analysis of geosynthetic-reinforced floating granular piles in soft clays. International Journal of Geosynthetics and Ground Engineering, no. 2(3), article number: 22, https:doi.org/10.1007/s40891-016-0062-6.

19. Bacas B.M., Cañizal J., Konietzky H., 2015. Frictional behaviour of three critical geosynthetic interfaces. Geosynthetics International, vol. 22, no. 5, pp. 355-365, https:doi.org/ 10.1680/jgein.15.00017.

20. Tajabadipour M., Marandi M., 2017. Effect of rubber tire chips-sand mixtures on performance of geosynthetic reinforced earth walls. Periodica Polytechnica Civil Engineering, vol. 61, pp. 322-334, https:doi.org/10.3311/PPci.9539.

21. Abd A., Utili S., 2017. Design of geosynthetic-reinforced slopes in cohesive backfills. Geotextiles and Geomembranes, no. 45(6), pp. 627-641, https:doi.org/10.1016/j.geotex mem.2017.08.004.

22. Kim M., Filz G.M., Plaut R.H., 2005. Two-chambered water-filled geomembrane tubes used as water barriers: experiments and analysis. Geosynthetics International, vol. 12, no. 3, pp. 127-133, https:doi.org/10.1680/gein.2005.12.3.127.

\section{Информация об авторе}

Д. В. Кашарин - доцент кафедры водного хозяйства, инженерных сетей и защиты окружающей среды, кандидат технических наук, доцент.

\section{Information about the author}

D. V. Kasharin - Associate Professor of the Department of Water Management, Engineering Networks and Environmental Protection, Candidate of Technical Sciences, Associate Professor.

Автор заявляет об отсутствии конфликта интересов.

The author declares no conflicts of interests.

Статья поступила в редакиию 30.08.2021; одобрена после рецензирования 11.11.2021; принята к публикации 15.11.2021.

The article was submitted 30.08.2021; approved after reviewing 11.11.2021; accepted for publication 15.11.2021. 